\title{
Nurses' perception of psychological empowerment and its relationship to work engagement and job insecurity
}

\author{
Ebtsam Aly Abou Hashish ${ }^{* 1,2}$, Neveen Hassan Abdel All ${ }^{3}$, Amal Awad Mousa ${ }^{3}$ \\ ${ }^{1}$ Faculty of Nursing, Alexandria University, Alexandria, Egypt \\ ${ }^{2}$ College of Nursing, King Saud bin Abdul-Aziz University for Health Sciences, Kingdom of Saudi Arabia \\ ${ }^{3}$ Faculty of Nursing, Damanhur University, Al-Behera, Egypt
}

Received: January 15, 2018

DOI: $10.5430 /$ jnep.v8n9p36
Accepted: April 7, 2018

URL: https://doi.org/10.5430/jnep.v8n9p36

\begin{abstract}
Background and objective: Psychological empowerment and work engagement are vital factors to consider when managing changes in workplace and enhancing both individual and overall organizational performance and increasing nurses' job security. This study aimed to explore how nurses perceive their psychological empowerment, work engagement, and job insecurity. Further, to investigate whether nurses' perception of psychological empowerment is related to their work engagement and job insecurity. Methods: A descriptive correlational research design was conducted using a convenience sample of nurses $(\mathrm{N}=400)$ working in Damanhur educational hospital, Egypt. Psychological Empowerment Questionnaire, Utrecht Work Engagement Scale, and Job Insecurity Inventory proved valid and reliable to measure study variables.

Results: The present study revealed that nurses experienced high psychological empowerment and work engagement and perceive a lower level of job insecurity. A significant positive correlation was found between nurses' perception of psychological empowerment and their work engagement. On the contrary, Job Insecurity was negatively correlated with each of psychological empowerment and work engagement $(p<.001)$. In addition, psychological empowerment and work engagement can significantly predict $6.6 \%$, and $9.3 \%$ of job insecurity respectively where the regression model is significant $(p<.001)$.

Conclusions: Nurses perceived their work environment as empowering and their work as challenging and stimulating, rending their competence, so they psychologically attached to and engaged in work and feel less job insecurity. Recommendations: Creating an atmosphere of trust and empowering nurses psychologically is inevitable. Hospital managers can adopt strategies that facilitate nurses' engagement and reduce the levels of job insecurity. Positive empowering work climate, social support, and nurse managers leadership styles are factors that foster work engagement and job security.
\end{abstract}

Key Words: Psychological empowerment, Work engagement, Job insecurity, Nurses, Hospitals

\section{INTRODUCTION}

As more organizations searching for individuals who step up and react in an innovative way to the workplace challenges, psychological empowerment and work engagement wind up plainly imperative particularly when managing change in work and enhancing work performance. Empowered and engaged individuals are for the most part happier with their work, conferred and compelling at work. ${ }^{[1]}$ Empowerment is the process by which a leader imparts energy to others or enables them to act. ${ }^{[2]}$ Chalk, Bijl and Halfens (2010) guaranteed that nurses could be enabled at all levels of the organizations. They announced that patient care quality and Egypt. 
safety relate straightforwardly to how empowered nurses are to impact patient care and add to the organizational decisions. ${ }^{[3]}$

Also, work engagement is a multifaceted term which incorporates the passionate and cognitive responsibility of nurses towards the organization. ${ }^{[4]}$ Comparably, when nurses encounter expanded psychological empowerment they effectively connect with, engaged in, and take an interest in leadership practices e.g. inventive practices, and amplified viability, thusly, increment the feeling of professional stability and job security. ${ }^{[5]}$

\subsection{Framework of the study}

The current study was guided by the conceptualizations of three work factors to be specific: psychological empowerment, work engagement and job insecurity. The following section illuminated them.

\subsubsection{Psychological empowerment}

Psychological empowerment has earned acknowledgment in management theories and practices. ${ }^{[6,7]}$ Additionally, it has picked up an expanded popularity in scholastics and nursing as a precursor of expanded efficiency and job satisfaction. ${ }^{[5]}$ Psychological empowerment reflects the individual inspiration driving the decision of getting to be plainly associated with the working environment and getting able to shape and frame their work roles. ${ }^{[7]}$

Spreitzer (1995) asserted that psychological empowerment showed in four determinants mirroring a person's orientation to his or her work role, namely: meaning, competence, selfdetermination, and impact. ${ }^{[7]}$ Meaning alludes to a feeling of purpose or individual attachment to work. Competence mirrors individuals' convictions that they have the fundamental aptitudes and capacities to play out their function admirably. Self-determination refers to a feeling of opportunity about how individuals do their function. Impact portrays a conviction that individuals can affect the framework in which they are involved. In addition to the achievement one feels in accomplishing objectives. ${ }^{[8]}$ These four determinants may influence organizational conduct and can likewise be viewed as psychological prerequisites could help individuals to feel more in charge and prompt work engagement. ${ }^{[7]}$

\subsubsection{Work engagement}

Engagement is a multifaceted concept which can be emotional, cognitive or physical. Work engagement is characterized as the emotional and intellectual commitment of employees towards the organization. ${ }^{[9,10]}$ Individual's engagement, for the most part, relies upon the mental aptitudes, the act of job, work conditions and foundation that shape the process through which individuals make themselves rationally

Published by Sciedu Press and physically displayed in the work environment amid the activity or work execution. ${ }^{[4]}$

Schaufeli et al. (2002) recognized three elements for work engagement to be specific; vigor, dedication, and absorption. Vigor is described by; high vitality levels and mental versatility when working, the readiness to put exertion in one's work, not getting to be plainly exhausted, and ingenuity even with the challenges. Dedication alludes to the solid inclusion in one's work, described by excitement and pride in one's activity, and feeling enlivened by it. Absorption is described by focusing completely on one's work. It indicates a charming state in which one is completely submerged in one's work, disregarding everything else. ${ }^{[10]}$

Work Engagement happens when the individual encounters cognitive conscientious, emotional and passionate warmth with other employees in the work environment and feel job security. ${ }^{[11]}$

\subsubsection{Job insecurity}

Job insecurity identifies with individuals in their work setting who expect that they may lose their occupations and end up noticeably jobless. Job insecurity is generally conceptualized as either a global or a multidimensional concept. As indicated by the global perspective, Job insecurity indicates the threat of job loss, job uncertainty or employment vulnerability. ${ }^{[12]}$ Job insecurity is a standout amongst the most distressful parts of the work circumstance. ${ }^{[13]}$

As indicated by De Witte (2000) job insecurity comprises two dimensions: cognitive and affective. Cognitive job insecurity relates to perceptions of possible job loss, whereas affective job insecurity relates to the fear of job loss. ${ }^{[14]}$ De Witte (1999) and Probst (2002) consider Job insecurity to be a work stressor which can bring about pressure responses, for example, negative states of mind to work. ${ }^{[12,13]}$ It is also identified with psychological well-being dissensions, brings down levels of employment fulfillment, and contribution, diminished trust and engagement and increased intention to leave. ${ }^{[15-17]}$

\subsection{Problem statement and significance of the study}

Nurses' work has been viewed as a very distressing work since they need to give additional time and effort and managerial concern. ${ }^{[18]}$ Employees who demonstrate separation or disengagement in work, their work practices and performance turn out to be low and they don't demonstrate any exertion or perform well. ${ }^{[4]}$ Disengaged employees are more disposed towards the withdrawal of cognizance and enthusiastic connection towards their obligation and work practices. ${ }^{[11]}$ This disengagement can be caused by the low empowered jobs or potentially when employees imagine that 
they do an irrelevant work and feel shaky about their activity. ${ }^{[4]}$

On the other hand, the experience of being empowered has been proposed to be an arbiter between managerial practices and the outcomes anticipated from empowered workers, such as engagement, organizational commitment, and job performance. ${ }^{[7,17]}$ In addition, despite the fact that a past research directed by De Cuyper et al. (2008) demonstrated that job insecurity related to work engagement, yet, a paucity of researches were available regarding nurses' psychological empowerment and its connection to work engagement and job insecurity. ${ }^{[19]}$ Little is known whether nurses' perception of psychological empowerment, work engagement is related to their perception of job insecurity ${ }^{[19]}$ particularly with regards to the context of Egyptian hospitals. Hence, a need exists to research this relationship. It is hoped that, by the investigation of the relationship between psychological empowerment, work engagement and job insecurity among nurses, it will add to nursing leaders' knowledge and behaviors to enhance empowered work environment and work engagement and reduce nurses' feeling of job insecurity.

\subsection{Research hypotheses}

Given that empowered nurses who trust in themselves and the work that they do, turn out to be more engaged and feel more secure in their job. The following hypotheses are formulated:

Hypothesis 1: Significant positive relationship exists between nurses' perception of psychological empowerment and their work engagement.

Hypothesis 2: Significant negative relationship exists between nurses' feeling of Job insecurity and their psychological empowerment and work engagement.

\subsection{Aim of the study}

The main aim of this study was to explore how nurses perceive their own psychological empowerment, work engagement and job insecurity at the workplace. Further, to investigate whether nurses' perception of psychological empowerment is related to their work engagement and job insecurity.

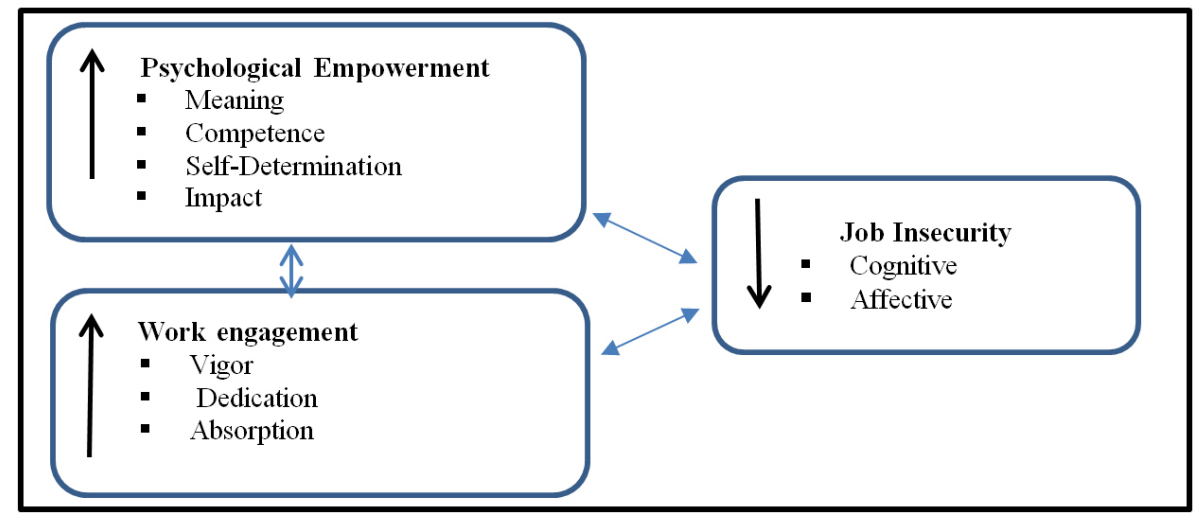

Figure 1. Suggested framework of the study

\section{MethodS}

\subsection{Research design and setting}

This study, conducted a descriptive correlational research design in all inpatient care units at Damanhur Educational Hospital, Al-Behera governorate, Egypt. Damanhur Educational hospital is the largest, nonprofit hospital with a bed capacity of 640 beds that provides all types of free health services for clients/patients coming from Al-Behera and many other governorates.

\subsection{Participants}

All nurses who are working in in-patient care units at the above-mentioned setting and available to participate in this study were included $(\mathrm{N}=400)$. The valid response rate was $86.26 \%$, representing 400 out of 524 nurses who participated in the study in addition to 52 nurses who included in the pilot study and excluded from the final responses.

\subsection{Measuring instruments}

Three instruments were used in this study.

1) Psychological Empowerment Questionnaire (PEQ) developed by Spreitzer (1995) was used to measure how nurses experience psychological empowerment in their workplace. It consists of 12 items on four subscales namely: meaning, competence, self-determination, and impact with three items for each subscale. Responses were measured using a sevenpoint Likert scale, ranged from 1 (strongly disagree) to 7 (strongly agree). The score ranged from 7 to 84 . Higher scores imply greater nurses' psychological empowerment. ${ }^{\text {[7] }}$

2) Utrecht Work Engagement Scale (UWES) developed by 
Schaufeli et al. (2002) was used to measure nurses' feeling of work engagement. It consists of 17 items including three dimensions: vigor (six items), dedication (five items), and absorption (six items). Responses were measured using a seven-point Likert scale, ranged from 0 (Never) to 6 (Very often). The score ranged from 6 to 102. The higher the score, the more nurses' engagement in their work. ${ }^{[10]}$

3) Job Insecurity Inventory (JII) developed by De Witte (2000) was used to measure nurses' feelings of job insecurity. It consists of 11 items that summaries both the cognitive (six items) and affective (five items) dimensions of job insecurity. Responses were measured using a five-point Likert scale ranged from 1 (strongly disagree) to 5 (strongly agree). The score ranged from 5 to 55 . High score indicates a high level of job insecurity. ${ }^{[14]}$

In addition, demographic and work-related characteristics form for nurses was developed by the researchers, including questions related to (age, gender, educational level, working unit, position, and years of experience).

\subsection{Validity and reliability}

The study tools were translated into the Arabic language to suit the Egyptian culture and tested for content validity along with the fluency of the translation by five experts in the field of study including, two Professors from psychiatric and mental health Nursing Department, and two Professors and a Lecturer from Nursing Administration Department. Accordingly, some statements were modified for more clarity. Tools also were tested for internal reliability using the Cronbach's alpha correlation coefficient. The results proved the tools were reliable with correlation coefficient $\alpha 0.808,0.765$ and 0.838 for PEQ, UWES and JII, respectively, while the statistical significance level was set at $p \leq .05$. In addition, a pilot study was conducted with 50 nurses $(10 \%)$ who were later excluded from the study subjects with no changes occurred in the final tools.

\subsection{Data collection}

Hospital approval was obtained to collect the study data. The researchers distributed the questionnaires to nurses in their working units. Each nurse took about 20 minutes to complete the questionnaires after giving the complete instructions. Data were collected from nurses after obtaining their consent. Data collection took five months, from December 2016 till March 2017.

\subsection{Ethical considerations}

Approval was obtained from Ethics Committee at Faculty of Nursing, Damanhur University. The researchers explained the aim of the research to all participants. The privacy and Published by Sciedu Press confidentiality of data were maintained. Participants' informed consent was assured. The anonymity of participants was granted.

\subsection{Statistical analysis}

Data were coded by the researchers and statistically analyzed using SPSS version 20. Frequency and percentages were used for describing demographic and work-related characteristics. Descriptive statistics (means and standard deviations) and Inferential statistics (Pearson product-moment correlation coefficient and Regression analysis $\left.\left[R^{2}\right]\right)$ were used to analyze the results of the study. Regression analysis $\left(R^{2}\right)$ was run to test the predictive power of independent variables (psychological empowerment) on the dependent variable (work engagement and job insecurity). $R^{2}$ change was tested with F-test. A significant $\mathrm{F}$ value for $R^{2}$ meant that the variables added significant prediction. All statistical analyses were performed using an alpha error of .05. The level of statistical significance was set at $p \leq .05$. Pearson correlation coefficient values indicated as follow: $r=0.1$ weak relationship, $r$ $=0.3$ moderate relationship, and $r=0.5$ strong relationship.

\section{RESULT}

\subsection{Nurses' demographic and work-related characteris- tics}

All study nurses were female. $40.0 \%$ of nurses were aged between 30 to less than 40 years old while $2.0 \%$ of them were less than 20 years old. The highest percentage of nurses (70.5\%) had a diploma of secondary nursing school, while $4.8 \%$ of them had a bachelor degree of nursing science. Moreover, $30.3 \%$ of nurses had more than 20 years of nursing experience, while $12.5 \%$ of them had less than 5 years of experience. Most of the nurses (95.2\%) were working as bedside nurses while $4.8 \%$ of them were working as senior nurses. $24.0 \%$ of nurses are working in surgical care units, while $14.8 \%$ of them were working in intensive care units (see Table 1).

\subsection{Nurses' perception of psychological empowerment,} work engagement, and job insecurity

Regarding nurses' perception of study variables, Table 2 reveals the mean percent score and standard deviation of nurses' perception of overall psychological empowerment represented as $82.22 \pm 12.21$ with the highest mean for competence dimension $(89.88 \pm 12.44)$ while, impact dimension come at the last with a mean represented by $74.25 \pm 18.54$. Moreover, nurses' perception of overall work engagement was represented by $78.01 \pm 13.14$ with the highest mean for dedication dimension (82.94 \pm 14.54$)$, while, absorption dimension come at the last with a mean represented by 74.01 \pm 14.31 . In addition, nurses' overall mean score of job in- 
security was $26.04 \pm 19.13$ while affective job insecurity had slightly higher mean $(29.65 \pm 27.07)$ than cognitive job insecurity $(23.03 \pm 16.41)$.

Table 1. Distribution of nurses according to demographic and work-related characteristics $(\mathrm{N}=400)$

\begin{tabular}{lll}
\hline Demographic Characteristics & No. & \% \\
\hline Age(years) & 8 & \\
Less than 20 & 126 & 31.5 \\
20- & 160 & 40.0 \\
30- & 75 & 18.7 \\
40- & 31 & 7.8 \\
More than 50 & & \\
Level of education & 19 & 4.8 \\
Bachelor degree of nursing science & 99 & 24.7 \\
Diploma of Technical Institute of nursing & 282 & 70.5 \\
Diploma of Secondary nursing school & & \\
Years of experience in nursing & 50 & 12.5 \\
Less than 5 years & 63 & 15.7 \\
5 years- & 60 & 15.0 \\
10 years- & 106 & 26.5 \\
15 years- & 121 & 30.3 \\
More than 20 years & & \\
Current occupational position & 381 & 95.2 \\
Bedside nurses & 19 & 4.8 \\
Senior nurses & & \\
Working unit & 85 & 21.2 \\
Medical & 96 & 24.0 \\
Surgical & 66 & 16.5 \\
OR & 59 & 14.8 \\
ICU & 94 & 23.5 \\
CCU & & \\
\hline
\end{tabular}

\subsection{Correlation between psychological empowerment,} work engagement, and job insecurity

Table 3 reveals significant positive moderate correlation between overall psychological empowerment and overall work engagement where $r=0.407, p<.001$. On the other hand, significant negative moderate correlations were found between overall job insecurity and each of overall psychological empowerment and overall work engagement where $r=-0.256$, $p<.001$ and $r=-0.305, p<.001$ respectively. The same trend of the result was reflected in the relationship among dimensions related to each variable. See supplementary Table 1.

Table 2. Nurses' perception of psychological empowerment, work engagement and job insecurity

\begin{tabular}{ll}
\hline Variables & Mean $\% \pm$ SD. \\
\hline Overall Psychological empowerment & $82.22 \pm 12.21$ \\
Meaning & $88.10 \pm 13.18$ \\
Competence & $89.88 \pm 12.44$ \\
Self-Determination & $80.92 \pm 19.06$ \\
Impact & $74.25 \pm 18.54$ \\
Overall Work Engagement & $78.01 \pm 13.14$ \\
Vigor & $77.92 \pm 18.50$ \\
Dedication & $82.94 \pm 14.54$ \\
Absorption & $74.01 \pm 14.31$ \\
Overall Job Insecurity & $26.04 \pm 19.13$ \\
Affective Job Insecurity & $29.65 \pm 27.07$ \\
Cognitive Job Insecurity & $23.03 \pm 16.41$ \\
\hline Note. SD: Standard Deviation &
\end{tabular}

\subsection{Regression analysis of psychological empowerment with work engagement and job insecurity}

Table 4 reveals regression coefficient values between psychological empowerment and each of work engagement and job insecurity. The value of regression coefficient between psychological empowerment and work engagement was 0.165 . This means that approximately $16.5 \%$ of the explained variance of nurses' work engagement can be predicted by their perception of psychological empowerment where the model is significant $(\mathrm{F}=78.867, p<.001)$. Moreover, psychological empowerment contributes independently to the explained variance and predicting about $6.6 \%$, of overall job insecurity where the model is significant $(\mathrm{F}=27.996, p<.001)$. Furthermore, the value of regression coefficient between overall work engagement and job insecurity was 0.093 . This means that approximately $9.3 \%$ of the explained variance of job insecurity can be predicted by their feeling of work engagement where the model is significant $(\mathrm{F}=40.918, p<$ $.001)$

Table 3. Correlation between psychological empowerment, work engagement and job insecurity

\begin{tabular}{lllll}
\hline Variables & & Overall Psychological empowerment & Overall work engagement & Overall Job insecurity \\
\hline Overall Psychological & $r$ & & $0.407^{*}$ & $<.001$ \\
empowerment & $p$ & & $-0.305^{*}$ \\
Overall work & $r$ & & $<.001$ \\
engagement & $p$ & & \\
Overall Job insecurity & $r$ & $-0.256^{*}$ & & \\
& $p$ & $<.001$ & & \\
\hline
\end{tabular}

Note. $r$ : Pearson correlation coefficient; *: Statistically significant at $p \leq .05$ 
Table 4. Regression analysis of psychological empowerment with work engagement and job insecurity

\begin{tabular}{lllllllll}
\hline Variables & $\mathbf{B}$ & $\mathbf{S E}$ & $\boldsymbol{t}$ & $\boldsymbol{p}$ & $\boldsymbol{R}$ & $\boldsymbol{R}^{2}$ & $\mathbf{F}$ & $\boldsymbol{p}$ \\
\hline Work engagement & 0.407 & 0.05 & $8.881^{*}$ & $<.001^{*}$ & 0.407 & 0.165 & $78.867^{*}$ & $<.001^{*}$ \\
Overall job insecurity & -0.256 & 0.07 & $5.291^{*}$ & $<.001^{*}$ & 0.256 & 0.066 & $27.996^{*}$ & $<.001^{*}$ \\
\hline \multicolumn{2}{l}{ Regression Analysis Between Work Engagement and Job Insecurity } & & & & \\
\hline Variables & $\mathbf{B}$ & $\mathbf{S E}$ & $\boldsymbol{t}$ & $\boldsymbol{p}$ & $\boldsymbol{R}$ & $\boldsymbol{R}^{2}$ & $\mathbf{F}$ & $\boldsymbol{p}$ \\
\hline Job insecurity & -0.305 & 0.03 & $6.397^{*}$ & $<.001^{*}$ & 0.305 & 0.093 & $40.918^{*}$ & $<.001^{*}$ \\
\hline
\end{tabular}

Note. B: the coefficient estimate; SE: standard error; $t$ : $t$-test value; $r$ : Pearson correlation coefficient; $R^{2}$ : regression coefficient; F: F-test (ANOVA); ANOVA: analysis of variance. *Statistically significant at $p \leq .05$.

\section{Discussion}

The result of the current study revealed that nurses highly experienced psychological empowerment and perceived that the level of nurses' empowerment is favorable from the respect of competence dimension followed by meaning, selfdetermination and impact dimensions. Nurses believe that competence is their source of power in the hospital and they mastered the necessary competence, skills, abilities, confidence, and sense of purpose to perform work activities and the assigned duties and career responsibilities efficiently. Similarly, Rawat (2011) proved, a feeling of capability gives workers the conviction that they can carry out their work roles with expertise and achievement, fortifying them to apply significant exertion for the organization. In addition, self-determination gives workers control over their work and a voice in work-related decision processes, leading to enhanced involvement in the organization. ${ }^{[20]}$ Likewise, Knol and VanLinge (2009) expressed that empowerment is an essential part of building a positive nursing work environment and exists when nurses believe in their role in the organization. ${ }^{[21]}$

The result of the present study is consistent with, Ibrahim et al. (2014) and Nasiripour and Siadati (2011) who indicated that the majority of nurses in their hospitals were perceived psychological empowerment positively. ${ }^{[2,22]}$ Comparatively, Seibert, Wang, and Courtright (2011) allude to the fact that a high level of psychological empowerment, brings greater satisfaction, and well-being at work, greater organizational commitment, and improved task performance. ${ }^{[23]}$ In this regard, Laschinger et al. (2010) emphasized the role of nurse managers to make conditions that nurses are enabled to provide quality care for the patients. ${ }^{[24]}$

Regarding work engagement, the result of the current study revealed that nurses are engaged in their work with the highest mean given to dedication dimension followed by vigor and absorption dimensions. These results may be attributed to nurses' perception and satisfaction with psychological empowerment they experienced in their work environment. When nurses reported their work as challenging, they have the enthusiasm to continue working for a long period of time and they happily immerse themselves in work making it difficult to detach them for work. In the same line, Laschinger et al. (2009) stated that, when nurses have tools for practice their work, they experience a greater energy and become more likely to be enthusiastic and proud of their care and engaged to work more. ${ }^{[25]}$ Likewise, Schaufeli et al., (2002) expressed that engaged employees have a sense of energetic and effective connection with their work activities and consider themselves to be ready to bargain totally with the requests of their activity. ${ }^{[10]}$ In this context, Chaudhary et al., (2011) underlined, employee engagement has developed as one path for organizations to gauge their interest in human capital. ${ }^{[26]}$ Besides, Sierra et al. (2015) proposed that positive work atmosphere, supportive organization and leadership styles are factors that encouraging work engagement. ${ }^{[27]}$

As regarding job insecurity, the result of this study revealed that nurses perceive a lower level of job insecurity, however, affective job insecurity had slightly a higher mean than cognitive job insecurity. Nurses expressed that job insecurity can just exist when they experience a danger of overall job loss, loss of any dimension of their job and the disintegration of any states of employment. This result concurred with Stander and Rothmann (2010) who found that employees were experiencing a higher level of uncertainty about their job continuity (affective job insecurity) than about the continuity of certain dimensions of their job (cognitive job insecurity). ${ }^{[16]}$ Additionally, Huang et al. (2012) and Ito and Brotheridge (2007) specified, job insecurity predicts both psychological wellbeing and job performance however cognitive job insecurity has the backhanded impact on performance. ${ }^{[28,29]}$

Supporting the research hypothesis 1 , the present study revealed that psychological empowerment and work engagement are positively and significantly correlated with each other. Positive correlations were found also between all dimensions of psychological empowerment (meaning, competence, determination, and impact) and all dimensions of work engagement (vigor, dedication, and absorption dimensions). This correlation was confirmed by the result of regression 
analysis, which revealed that psychological empowerment can predict $16.5 \%$ of work engagement in a statistically significant positive way. These results implied, empowered and competent nurses feel more satisfied in their work and experience larger amounts of connection and work engagement. Our results concur with Moura et al. (2015) who found that psychological empowerment and work engagement are forcefully and fundamentally related. ${ }^{[1]}$

Likewise, Imam and Hassan (2015) demonstrated that there was a noteworthy positive effect of psychological empowerment on work engagement which impacts nurses' satisfaction in a positive way. ${ }^{[4]}$ Moreover, Stander and Rothmann (2010) revealed, the standardized regression coefficients confirmed that psychological empowerment predicted individual engagement. Additionally, announced that an empowering work environment was strongly predictive of nurses' feelings of effectiveness and engagement with the work. ${ }^{[16]}$ In such regard, Greco et al., (2006) prescribed that organization should execute intervention to ensure the psychological empowerment of employees. Nursing administrators and supervisors assume a vital part in making connecting with workplaces in which nurses encounter their work as significant and where they feel that they can impact the work productivity. ${ }^{[30]}$

On the other hand, negative correlations between job insecurity and each of psychological empowerment and work engagement were found. This correlation also confirmed by the negative prediction which highlighted in the regression analysis model among these variables. Increased level of psychological empowerment and work engagement will decrease the sense of job insecurity. As nurses' experience empowerment in their work, they become more engaged and feel secure about their work roles. This result supports the research hypothesis 2. Similarly, De Cuyper et al. (2008) proved that job insecurity to be a measurable critical factor that was adversely identified with worker engagement. ${ }^{[19]}$ Contradicting, Cho, Laschinger, and Wong (2006), revealed that empowerment had an immediate positive effect on work life, which thusly, contrarily influencing emotional exhaustion. ${ }^{[31]}$ Likewise, Greasley et al. (2005) found that engaged workers experience lessened levels of job insecurity. ${ }^{[32]}$ In this regard, Probst (2002) concurred that lack of psychological empowerment without a doubt is an imperative variable in the investigation of job insecurity. ${ }^{[13]}$

\section{CONCLUSION AND RECOMMENDATIONS}

To sum up, the present study indicated that nurses perceived their work environment as empowering and their work as challenging and stimulating them to be more competent, so they psychologically attach and engage in their work and feel secure in their job. This resulted is supported by the sig- nificant positive correlation and prediction power that found between psychological empowerment and work engagement. On the contrarily, job insecurity was negatively correlated with each of nurses' psychological empowerment and work engagement.

\subsection{Strengths and limitations}

The present investigation could be considered as one of the vital researches to analyze the relationship between psychological empowerment, employee engagement, and job insecurity. These results provide an additional evidence that psychological empowerment assumes a significant impact and an imperative part in the conditions that go before work engagement and job insecurity. Also, the study emphasized the role of nursing leaders' endeavors to make empowering workplaces can impact the nurses' capacity to practice in a professional manner, guaranteeing amazing patient care quality and positive organizational outcomes.

Despite its contributions, various limitations in this study should be highlighted. To start with, the cross-sectional nature of the investigation constrained the findings to demonstrate proof of causal connections. Second, this investigation depends on self-reports, which may build the danger of bias. At last, just a single strategy for data collection (questionnaires) was utilized. These impediments might be thought about open doors for future inquiry.

\subsection{Recommendation}

In the light of the result of this study, certain recommendations are highlighted.

- The Hospital and Nurse Managers should work to create an atmosphere of trust and empower nurses psychologically to bring out their best in favor of their patients and organizations. Empowerment intervention programs may play a crucial role in understanding employees' adaptation in their work environment.

- The Hospital and Nurse Managers should adopt a strategy that facilitates the workforce engagement and to reduce the levels of job insecurity to increase organizational outcomes and effectiveness. Positive work climate, organizational support and leadership styles are factors that fostering work engagement and job security.

- Future studies are recommended to investigate the effect of psychological empowerment and employee engagement on other variables such as staff turnover, absenteeism, performance, and safety. Future research is also suggested to identify the influence of nurses' demographic and work-related characteristics on the perception of these variables. Furthermore, studies also

ISSN 1925-4040 E-ISSN 1925-4059 
necessary to employ longitudinal designs, in different work contexts with different samples and at different organizational levels, would allow more sophisticated statistical analyses for speculation and generalization of the finding.

\section{CONFLICTS OF INTEREST Disclosure}

The authors declare that there is no conflict of interest.

\section{REFERENCES}

[1] Moura D, Orgambídez-Ramos A, de-Jesus S. Psychological empowerment and work engagement as predictors of work satisfaction: A sample of Hotel Employees. Journal of Spatial and Organizational Dynamics. 2015; 3(2): 125-134.

[2] Ibrahim M, Abo El-Magd M, Sayed H. Nurse's psychological empowerment and perceived autonomy in university and teaching hospitals at Menofia Governorate/Egypt. Journal of Nursing Education and Practice. 2014; 4(9): 59-68. https://doi.org/10.5430/jnep.v $4 \mathrm{n} 9 \mathrm{p} 59$

[3] Chalk D, Bijl M, Halfens R. Interventions aimed at improving the nursing work environment: a systematic review. Implementation Science. 2010; 5: 34. PMid:20423492 https://doi.org/10.1186/ 1748-5908-5-34

[4] Imam A, Hassan S. Psychological empowerment and engagement resulting in job satisfaction of employees working in service industry of Pakistan: a study of nursing staff. Sci. Int (Lahore). 2015; 27(3): 2695-2702.

[5] Spreitzer M, Quinn E. A Company of Leaders: Fine discipline for unleashing the power in your workforce. San Francisco, California: Jossey-Boss; 2001.

[6] Hall M. The effect of comprehensive performance measurement systems on role clarity, psychological empowerment and managerial performance. Accounting, Organizations and Society. 2008; 33(2-3): 141-163. https://doi.org/10.1016/j.aos. 2007.02.004

[7] Spreitzer M. Psychological empowerment in the workplace: Dimensions, Measurement, and Validation. Academy of Management Journal. 1995; 38(5): 1442-1465. https://doi .org/10.2307/25 6865

[8] Mishra K, Spreitzer M. E-planning how survivors respond to downsizing: the roles of trust, empowerment, justice, and work redesign. Academy of Management Review. 1998; 22: 567-588.

[9] Richman A. Everyone wants an engaged workforce how can you create it? Workspan. 2006; 36-39.

[10] Schaufeli B, Salanova M, Gon Zales-Roma V, et al. The measurement of engagement and burnout. A confirmatory factor analytic approach. Journal of Happiness Studies. 2002; 3: 71-92. https://doi.org/10.1023/A:1015630930326

[11] Luthans F, Peterson J. Employee engagement and manager self efficacy: Implications for managerial effectiveness. Journal of Management Development. 2002; 21(5): 376-387. https ://doi .org/10 $.1108 / 02621710210426864$

[12] De Witte H. Job insecurity and psychological well-being: Review of the literature and exploration of some unresolved issues. European Journal of Work and Organizational Psychology. 1999; 8: 155-177. https://doi.org/10.1080/135943299398302

[13] Probst M. The impact of job insecurity on employee work attitudes, job adaptation, and organizational withdrawal behaviors. In. Brett $\mathrm{M}$ \& Drasgow F (Eds.), The psychology of work: Theoretically based empirical research. New Jersey: Lawrence Erlbaum Associates; 2002.

[14] De Witte H. Arbeidethos en jobonzekerheid: Meting en gevolgen voor welzijn, tevredenheid en inzet op het werk. [Labour ethics and job insecurity: Measurement and consequences for well-being, satisfaction and labour input]. 2000. In R. Bouwen, K. de Witte, H. de Witte \& T. Taillieu (Eds.), Van groep tot gemeenschap. Liber Amicorum Prof. Dr L. Lagrou. Leuven: Garant.

[15] De Cuyper N, De Witte H. Job insecurity: mediator or moderator of the relationship between type of contract and various outcomes. South African Journal of Industrial Psychology. 2005; 31(4): 79-86. https://doi.org/10.4102/sajip.v31i4.211

[16] Stander W, Rothmann S. Psychological empowerment, job insecurity and employee engagement. S.A Journal of Industrial Psychology. 2010; 36(1): 849-857. https://doi.org/10.4102/sajip.v36i 1.849

[17] Stander W, Rothmann S. Leadership, job satisfaction and organizational commitment. South African Journal of Human Resource Management. 2008; 6(3): 7-13.

[18] Kaufman K. Headlines from the NLN. Introducing the NLN/Carnegie National Survey of Nurse Educators: Compensation, Workload, and Teaching Practice. Nursing Education Perspectives. 2007; 28(3): 164167. PMid:17557639

[19] De Cuyper N, Bernhard-Oettel C, Berntson E, et al. Employability and employee's well-being: Mediation by job insecurity. Applied Psychology: An International Review. 2008; 57: 488-509. https://doi.org/10.1111/j.1464-0597.2008.00332.x

[20] Rawat P. Effect of Psychological Empowerment on Commitment of Employees: An Empirical Study. 2011 2nd International Conference on Humanities, Historical and Social Sciences IPEDR. 2011; 17: 143-147.

[21] Knol J, Van Linge R. Innovative behavior: The effect of structural and psychological empowerment on nurses. Journal of Advanced Nursing. 2009; 65: 359-370. PMid:19191936 https ://doi .org/ $10.1111 / j .1365-2648.2008 .04876 . x$

[22] Nasiripour A, Siadati S. A proposed model for nurses' empowerment through characteristics of work place and management strategies, a study in Iranian Hospitals. Australian Journal of Basic and Applied Science. 2011; 5(6): 906-911.

[23] Seibert S, Wang G, Courtright S. Antecedents and consequences of psychological and team empowerment in organizations: A metaanalytic review. Journal of Applied Psychology. 2011; 96(5): 9811003. PMid:21443317 https ://doi .org/10.1037/a0022676

[24] Laschinger S, Gilbert S, Smith M, et al. Towards a Comprehensive Theory of Nurse/Patient Empowerment: Applying Kanter's Empowerment Theory to Patient Care. Journal of Nursing Management. 2010; 18: 4-13. PMid:20465724 https://doi.org/10.1111/j. 1365-2834.2009.01046.x

[25] Laschinger K, Wilk P, Cho J, et al. Empowerment, engagement and perceived effectiveness in nursing work environments: does experience matter? Journal of Nursing Management. 2009; 17: 636-646. PMid:19575722 https://doi .org/10.1111/j.1365-2834.20 $08.00907 . \mathrm{x}$

[26] Chaudhary R, Rangnekar S, Barua M. Relation between human resource development climate and employee engagement: Results 
from India. European Journal of Psychology. 2011; 7(4): 664-685. https://doi.org/10.5964/ejop.v7i4.158

[27] Sierra R, Castro J, Zaragoza F. Work engagement in nursing: an integrative review of the literature. Journal of Nursing Management. 2015; 24(2): 101-111. PMid:26032875 https://doi.org/10.1 $111 /$ jonm. 12312

[28] Huang G, Niu X, Lee C, et al. Differentiating cognitive and affective job insecurity antecedents and outcomes. Journal of Organizational Behavior. 2012; 33: 752-769. https://doi.org/10.1002/job. 1815

[29] Ito K, Brotheridge C. Exploring the predictors and consequences of job insecurity's components. Journal of Managerial Psychology.
2007; 22(1): 40-64. https://doi.org/10.1108/026839407107 21938

[30] Greco P, Laschniger K, Wong E. Leader empowering behaviors, nurses' empowerment and work engagement/burnout. Nursing Research. 2006; 19 (4): 41-56.

[31] Cho J, Laschinger S, Wong C. Workplace empowerment, work engagement and organizational commitment of new graduate nurses. Nursing Leadership. 2006; 19 (3): 43-60. PMid:17039996 https : //doi.org/10.12927/cjnl.2006.18368

[32] Greasley K, Bryman A, Price A, et al. Employee perceptions of empowerment. Employee Relations. 2005; 27: 354-368. https: //doi.org/10.1108/01425450510605697 